\title{
Food quality and nutraceutical value of nine cultivars of mango (Mangifera indica L.) fruits grown in Mediterranean subtropical environment
}

\author{
Carla Gentile ${ }^{a, *}$,Emanuela Di Gregorio ${ }^{a}$, Vita Di Stefano ${ }^{a}$, Giuseppe Mannino ${ }^{b}$, Anna Perrone ${ }^{\mathrm{a}}$, \\ Giuseppe Avellone $^{\mathrm{a}}$, Giuseppe Sortino ${ }^{\mathrm{c}}$, Paolo Inglese ${ }^{\mathrm{c}}$, Vittorio Farina ${ }^{\mathrm{c}}$ \\ ${ }^{a}$ Department of Biological, Chemical and Pharmaceutical Sciences and Technologies (STEBICEF), University of Palermo, Viale delle Scienze, 90128 Palermo, Italy \\ ${ }^{\mathrm{b}}$ Department of Life Sciences and Systems Biology, Innovation Centre, University of Turin, Via Quarello 15/A, Turin 10135, Italy \\ ${ }^{\mathrm{c}}$ Department of Agricultural, Food and Forest Sciences (SAAF), University of Palermo, Viale delle Scienze, 90128 Palermo, Italy
}

\section{A R T I C L E I N F O}

Chemical compounds studied in this article: Apigenin (PubChem CID: 5280443)

Benzoic acid (PubChem CID: 243)

Caffeic acid (PubChem CID: 689043)

Ferulic acid (PubChem CID: 445858)

Gallic acid (PubChem CID: 370)

Mangiferin (PubChem CID: 5281647)

P-coumaric acid (PubChem CID: 637542)

Syringic acid (PubChem CID: 10742)

Vanillin (PubChem CID: 1183)

Keywords:

Antioxidant activity

Mangiferin

Phytochemicals

Sensory profile

\begin{abstract}
A B S T R A C T
Mango (Mangifera indica L.) quality is strongly influenced by genotype but individuating the most appropriate harvesting time is essential to obtain high quality fruits. In this trial we studied the influences of the ripening stage at harvest (mature-ripe or green-ripe) on quality of ready to eat mango fruits from nine cultivars (Carrie, Keitt, Glenn, Manzanillo, Maya, Rosa, Osteen, Tommy Atkins and Kensington Pride) grown in the Mediterranean subtropical climate through physicochemical, nutraceutical, and sensory analysis. Our results show a large variability among the different observed genotypes and in dependence of the ripening stage at harvest. With the exception of Rosa, mature-ripe fruits are well-colored, sweet and aromatic, and better suited for short supply chains. On the other hand, post-harvest ripened fruits are firmer, frequently (Carrie, Glenn, Keitt, Manzanillo, Maya) possess interesting nutraceutical value and, in the case of Glenn, Maya, Osteen, and Kensington Pride, they can reach market standard quality.
\end{abstract}

\section{Introduction}

Mango (Mangifera indica L. Family Anacardiaceae) is the most diffused fruit crop in the tropical and subtropical areas of the world. It is cultivated on an area of approximately 3.7 million ha worldwide with over 1000 cultivars (CVs). Its production is concentrated in tropical, subtropical and, more recently, in the Mediterranean area. Along the coastal areas of Sicily, characterized by a mild climate, mango cultivation is increasing and, in the last decade, several international CVs were introduced (Farina, D’Asaro, Mazzaglia, Gianguzzi, \& Palazzolo, 2017a).

Fruit quality attributes, such as color, aroma, flavor, taste, and texture, are of great commercial importance (Farina, Gianguzzi, D'Asaro, Mazzaglia, \& Palazzolo, 2017b). On the other hand, due to the increasing consumer interest in health-promoting properties of food, also aspects related to nutraceutical value contribute to define fruit quality. Mango fruit is a rich source of phytochemicals (López-Cobo et al., 2017; Pott, Marx, Neidhart, Mühlbauer, \& Carle, 2003; Ribeiro,
Barbosa, Queiroz, Knödler, \& Schieber, 2008) and it has been included in the top ten of the fruits with the highest radical scavenging activity (Ali, Devi, Nayan, Chanu, \& Ralte, 2010). Commercial attributes of mango fruit are strongly dependent on genotype, climatic factors (Ribeir et al., 2008; Rocha Ribeiro et al., 2007) and storage conditions (Farina et al., 2017c). Moreover, mango quality is also influenced by ripening stage at harvest and after storage (Wanitchang, Terdwongworakul, Wanitchang, \& Nakawajana, 2011). Mango is a climacteric fruit with a very short shelf life due to its rapid ripeness after harvest. Usually, fruits from tropical countries and direct to the European market are collected precociously, before complete ripening, at mature-green stage, when they are hard and green, and then are ripen progressively after harvest. This practice improves storability and transportability but generally produces fruits lacking developed characteristic color, aroma and taste. On the other hand, fruits sent to local markets, and eventually air-shipped, can also be harvested at matureripe stage, and generally have the best quality. Even though data about fruit quality of mango can be found in the literature, a comparison

\footnotetext{
* Corresponding author.

E-mail address: carla.gentile@unipa.it (C. Gentile).
} 
between ripening on tree and after harvest had not been studied. Moreover, although studies were performed in the main tropical and subtropical environments (Liu et al., 2013; Mirellys et al., 2015), research is deficient in Mediterranean subtropical climate. In particular, until now, little reports are available on chemical composition and sensory parameters of several varieties recently introduced and grown in Sicily (Farina et al., 2017a). The aim of this trial is to understand the influence of the ripening on the tree or after harvest on the physicochemical, nutraceutical and sensory characteristics of mango fruits from nine CVs grown in the Mediterranean subtropical climate of Sicily. The secondary objective of the trial is to classify these different kinds of mango fruits based on their quality attributes.

\section{Materials and methods}

\subsection{Plant material}

The trial was carried out in the experimental orchard of the Cupitur Farm located in Acquedolci, province of Messina (Sicily, Italy; $38^{\circ} 3^{\prime} \mathrm{N}$, $14^{\circ} 33^{\prime} \mathrm{E} ; 5 \mathrm{~m}$ a.s.1.) in 2015. Nine CVs of mango were studied: Carrie, Keitt, Glenn, Manzanillo, Maya, Rosa, Osteen, Tommy Atkins and Kensington Pride (Supporting Information: SUPP1). Six uniform 11-yearold trees, grafted on Gomera- 3 rootstock, trained to a globe shape, were selected for each cultivar (CV). The trees were planted in single rows (north-south oriented), spaced $5 \times 4 \mathrm{~m}$ and submitted to the organic farming techniques. A sample of 30 fruits per CV ( 5 fruits $\times 6$ tree) were hand-picked at mature-green stage. Changes in fruit shape, from oval to round, depending on the $\mathrm{CV}$, were used as maturity index according to Galan-Sauco (Galan Sauco, 2009). Another sample of 30 fruits ( 5 fruits $\times 6$ tree $\times \mathrm{CV}$ ) were hand-picked at mature-ripe (MAT fruits) stage. MAT fruits are ready for harvesting when the upper edges of the fruit slightly overhang the point of insertion of the stalk. Moreover, in some observed CV, such as Tommy Atkins, skin color evolution from dark-green to light-green to yellow was used too as harvesting criteria (Galan Sauco \& Fernandez Galvan, 1990; Galan Sauco, 2009; Kader \& Mitcham, 2008). Twenty of these fruits were used for physicochemical and sensory analysis, while the other ten fruits were washed, peeled, and the pulp immediately frozen in liquid nitrogen and then stored at $-80^{\circ} \mathrm{C}$ and used for nutraceutical evaluation within 3 months. While MAT fruits were collected and immediately evaluated or frozen, those harvested at mature-green were before stored at room temperature $\left(25^{\circ} \mathrm{C}\right)$ until they were reached ready to eat maturation for 4-8 days (GRN fruits) and then were submitted to analysis or were frozen.

\subsection{Standard and chemicals}

Ascorbic acid (AA), [2,2'-azinobis(3-ethylbenzothiazoline-6-sulfonic acid)] diammonium salt (ABTS), 2,2'-azobis (2-methylpropionamidine) dihydrochloride (ABAP), 2',7'-dichlorofluorescein diacetate (DCFHDA), Folin-Ciocalteau's reagent, Hanks' balanced salt solution (HBSS), 6-hydroxy-2,5,7,8-tetramethylchroman-2-carboxylic acid (Trolox), potassium persulfate, and phenolic standards (apigenin, benzoic acid, caffeic acid, cinnamic acid, $p$-coumaric acid, ferulic acid, gallic acid, $p$ hydroxybenzoic acid, luteolin, mangiferin, protocatechuic acid, syringic acid, vanillic acid, vanillin) were purchased from Sigma-Aldrich (Gillingham, UK). $\beta$-Carotene was obtained from Extrasynthese (Genay, France). Acetonitrile, acetone and methanol (LC-MS grade) were purchased from Biosolve B.V. (Valkenswaard, The Netherlands) and acetic and formic acid from VWR International B.V. (Roden, The Netherlands). RPMI, fetal bovine serum (FBS), phosphate buffered saline (PBS), L-glutamine solution $(200 \mathrm{mM})$, trypsin-EDTA solution $(170,000 \mathrm{U} / 1$ trypsin and $0.2 \mathrm{~g} / 1$ EDTA) and penicillin-streptomycin solution $(10,000 \mathrm{U} / \mathrm{mL}$ penicillin and $10 \mathrm{mg} / \mathrm{mL}$ streptomycin) were purchased from Lonza (Verviers, Belgium). All other materials and solvents were of analytical grade unless indicated otherwise.

\subsection{Physiochemical analyses}

Fruit weight, longitudinal diameter, transversal diameter, seed weight, peel weight, flesh weight, flesh firmness (FF), total soluble solids content (TSS), and titratable acidity (TA), were analyzed. The weight of fruit, seeds, peel and flesh ( $\mathrm{g}$ ) were determined by a digital scale (Gibertini EU-C 2002 RS, Novate Milanese, Italy); the longitudinal and transversal diameter (mm) by digital caliper TR53307 (Turoni, Forlì, Italy); FF $\left(\mathrm{kg} \mathrm{cm}^{-2}\right)$ by digital penetrometer TR5325 with a $8 \mathrm{~mm}$ diameter tip (Turoni, Forlì, Italy); TSS ( ${ }^{\circ} \mathrm{Brix}$ ) by digital refractometer Atago Palette PR-32 (Atago Co., Ltd, Tokyo, Japan) and TA (g citric acid/L) using a Crisons compact tritator (Crison Instruments, SA, Barcelona, Spain).

\subsection{Vitamin $C$ content}

The Vitamin C content (VC) was determined by HPLC-DAD with spectrophotometric detection at $266 \mathrm{~nm}$. The liquid chromatographic system was equipped with an injector Model 77-25 (Rheodyne, Berkely, CA) with a $100 \mu \mathrm{L}$ injector loop, a photodiode detector, and a $5 \mu \mathrm{m}$ Chromsep C18 column ( $250 \mathrm{~mm} \times 4.6 \mathrm{~mm}$ i.d.) and a similarly packed pre-column (Varian, Palo Alto, CA). The elution was performed with a buffer solution consisting of $\mathrm{KH}_{2} \mathrm{PO}_{4} / \mathrm{H}_{3} \mathrm{PO}_{4}$ at $\mathrm{pH} 2.3$ and at a flow rate of $1.2 \mathrm{~mL} \mathrm{~min}^{-1}$. Three aliquots of a homogenate, obtained from thawed flesh of three fruits for each CV and for each series, GRN or MAT, where analyzed. Five $g$ of fruit flesh homogenate were added to $25 \mathrm{~mL}$ of $3 \%$ metaphosphoric acid, centrifuged, filtered through a Millex HV $0.45 \mu \mathrm{m}$ filter (Millipore, Billerica, MA) and injected in HPLC. The concentration of vitamin C was calculated from the experimental peak area by analytical interpolation in a standard calibration curve, and VC was expressed as mg AA per $100 \mathrm{~g}$ per fresh flesh weight $(\mathrm{FW})$. All measurements were done in three replicates.

\subsection{Total carotenoid content}

The total carotenoid content (TCC) was determined by spectrophotometric analysis after preliminary carotenoids extraction as previously reported (Gentile et al, 2016). All procedures were carried out on ice and under dim light as much as possible. Three aliquot of fruits flesh (ca. $5 \mathrm{~g}$ per aliquot) were analyzed. Each aliquot, obtained from 3 fruits for each CV and for each series MAT or GRN, previously ground to a fine powder under liquid nitrogen, was mixed for $20 \mathrm{~min}$ with $50 \mathrm{~mL}$ of extracting solvent (hexane/acetone/ethanol, 50:25:25, v/v/v). The organic phase containing carotenoids was recovered and then used for analyses after suitable dilution with hexane. Visible spectra were collected and TCC was evaluated by the absorbance at $450 \mathrm{~nm}$. TCC was calculated according to the method of Ritter and Purcell (Bauernfeind, 1981) using an molar extinction coefficient of $\beta$-carotene of 2505 and was expressed as $\mu \mathrm{g} \beta$-carotene per $\mathrm{g}$ FW. All measurements were done in three replicates.

\subsection{Preparation of the fruit extracts}

The fruits were thawed, peeled and the seed was removed. The pulp was finely chopped and weighed. Three different samples of a homogenate of three fruits for each series, GRN or MAT, were analyzed for each CV. Five $g$ of flesh homogenate was extracted for two times with $5 \mathrm{~mL}$ ethanol. After a cleanup step via centrifugation $(10 \mathrm{~min}$ at $10,000 \mathrm{~g}, 4^{\circ} \mathrm{C}$ ) and filtration through a Millex $\mathrm{HV} 0.45 \mu \mathrm{m}$ filter (Millipore, Billerica, MA), the supernatants were recovered, combined and used for the analysis detailed in the following sections.

\subsection{Total phenolic content}

The total phenolic content (TPC) of ethanolic extracts was determined by the reduction of phosphotungstic-phosphomolybdic acid 
(Folin-Ciocalteau's reagent) to blue pigments, in alkaline solution according to Folin and Denis (Singleton \& Rossi, 1965). Quantification was performed by gallic acid (GA) calibration curve, and the results were expressed as mg GA equivalents (GAE) per $100 \mathrm{~g}$ FW. All measurements were done in three replicates.

\subsection{Identification and quantification of phenolic compounds by UHPLC- HESI-MS/MS}

Polyphenolic profile of ethanolic extracts was performed by ultra high pressure liquid chromatography (UHPLC). The analysis was conducted using Dionex UltiMate ${ }^{\circledR} 3000$ Rapid Separation LC system (Thermo Fischer Scientific, San Jose, CA), with an auto-sampler controlled by Chromeleon 7.2 Software (Thermo Fisher, Bremen, DE and Dionex Softron $\mathrm{GmbH}$, Germering, DE). The column was a Phenomenex Luna C18(2) $50 \times 1 \mathrm{~mm}$, packed with core-shell particles of $2.5 \mu$. The flow rate was set at $50 \mu \mathrm{L} \mathrm{min}^{-1}$ at $20^{\circ} \mathrm{C}$ and the total chromatographic analysis time was $22 \mathrm{~min}$. The eluent A was water with $0.1 \%$ formic acid $(\mathrm{v} / \mathrm{v}) \mathrm{pH} 3.2$, and eluent $\mathrm{B}$ was acetonitrile with $0.1 \%$ formic acid $(\mathrm{v} / \mathrm{v})$. The elution was performed according to the following method: 0-10 min 5\% B; 10-13 min linear increase to $95 \% \mathrm{~B} ; 13-20 \mathrm{~min}$ hold $95 \%$ B; 21 min linear decrease $5 \%$ B and 22 min coming back to the initial conditions. The UHPLC was coupled to a quadrupole Orbitrap mass spectrometer ( $Q$ Exactive) (Thermo Scientific, Germany), equipped with heated electrospray ion source (HESI). For the identification of phenolic compounds negative ionization mode was used (Di Stefano et al., 2012). The HESI parameters were: auxiliary gas unit flow rate 4 arbitrary units; sheath gas flow rate 35 arbitrary units, capillary temperature $250{ }^{\circ} \mathrm{C}$; spray voltage $3.5 \mathrm{kV}$; auxiliary gas heater temperature $150^{\circ} \mathrm{C}$ and $\mathrm{S}$ lens RF level 30 . The MS was operated in electrospray negative, the analyses were conducted in two acquisition modes: Full-Scan, for untargeted analysis, and Selected Ion Monitoring (SIM) for quantification of the selected compounds. The resolution power in full scan was 35,000 FWHM (at $m / z 200$ ) and the scan range chosen was $100-1000 \mathrm{~m} / z$. The automatic gain control (AGC) target was set at $1 \mathrm{E} 5$ for a maximum capacity in C-trap and maximum injection time at $200 \mathrm{~ms}$. Scan-rate was set at $2 \mathrm{scans} \mathrm{s}^{-1}$. For SIM acquisition mode, the analysis was performed using a mass inclusion list and retention times of the singular target phenolic compounds (Supporting Information: SUPP2). The resolving power was 35,000 FWHM (at 200). Using this scan mode, precursor ions were filtered by the quadrupole with a $1 \mathrm{~m} / \mathrm{z}$ isolation window and the maximum injection time was $100 \mathrm{~ms}$. Data were analyzed with Qual Browser Xcalibur 3.0 (Thermo Fisher Scientific), and identification of individual phenolic was supported by retention times, exact mass spectral data. Quantification was performed by linear regression using an external calibration curves, injecting each phenolic standard suspended in 80:20 $\mathrm{MetOH} / \mathrm{H}_{2} \mathrm{O}(\mathrm{v} / \mathrm{v})$. Calibration curves were injected in quadruplicate.

\subsection{Total antioxidant activity}

The total antioxidant activity (TAA) of ethanol extracts was evaluated using the ABTS radical cation decolorization assay (Miller \& RiceEvans, 1996). ABTS $^{+}$was prepared by reacting of ABTS with potassium persulfate (Re et al., 1999). Samples were analyzed at five different dilutions, within the linearity range of the assay. TAA was expressed as $\mu \mathrm{mol}$ Trolox equivalent (TE) per $100 \mathrm{FW}$. All measurements were repeated three times.

\subsection{Cellular antioxidant activity}

The ethanolic extracts was submitted to the Cellular Antioxidant Activity (CAA) assay. For the experiments we used cell line HepG2 (hepatocarcinoma cells), obtained from American Type Culture Collection (ATCC) (Rockville, MD, USA). The cells were cultured in RPMI supplemented with $5 \%$ FBS, $2 \mathrm{mM}$ L-glutamine, $50 \mathrm{IU} / \mathrm{mL}$ penicillin, and $50 \mu \mathrm{g} / \mathrm{mL}$ streptomycin and maintained in a humidified atmosphere with $5 \% \mathrm{CO}_{2}$ at $37^{\circ} \mathrm{C}$. The cells were routinely cultured in $75 \mathrm{~cm}^{2}$ culture flasks and were trypsinized using trypsin-EDTA when the cells reached approximately $80 \%$ confluence. CAA assay was performed as previously described (Wolfe \& Liu, 2007). EtOH concentration in each experiment never exceeded $0.25 \%$ and culture medium with $0.25 \% \mathrm{EtOH}$ was used as control. The area under the curve of fluorescence versus time was integrated to calculate the CAA value at each concentration of fruit extract as follows:

$C A A=100-\left(\int S A \int C A\right) * 100$

where: $\int \mathrm{SA}$ is the integrated area from sample curve; $\int \mathrm{CA}$ is the integrated area from the control curve. The concentration necessary for $50 \%$ of diclorofluorescein formation inhibition (CAA50) for each extract or pure GA was calculated from concentration-response (CAA) curves using linear regression analysis. Each result was the mean value of three separate experiments performed in triplicate.

\subsection{Sensory analysis}

The sensory profile was defined by a panel of 10 judges ( 4 male and 6 female, aged between 25 and $37 \mathrm{y}$ ). All panelists were trained and had a broad expertise in sensory evaluation of foods. Panel members were trained using different samples of mango to recognize the qualitative characteristics to be assessed and to generate the attributes. Besides, the judges were trained on aroma, flavor, textural and mouth feel attributes during the trained session, using product and ingredient references. The samples were evaluated using 10 attributes (Supporting Information: SUPP3). About $50 \mathrm{~g}$ of samples was dispensed into a small plastic plate with a 3-digit code on the side and served to judges. The judges evaluated the intensity of each descriptor by assigning categorical scores of 1 (absence of sensation), 2 (just recognizable), 3 (very weak), 4 (weak), 5 (slight), 6 (moderate), 7 (intense), 8 (very intense) and 9 (extremely intense). The study was carried out during three months (from August to October). The sample order for each panelist was randomized and water was provided for rinsing between mango samples.

\subsection{Statistical analysis}

All data were tested for differences between the CVs using the oneway analysis of variance (ANOVA; general linear model) followed by Tukey's multiple range test for $\mathrm{P} \leq 0.05$, whereas Student's-test was used to determine the difference GRN and MAT fruits. Principal Component Analysis (PCA) was performed by using covariant matrix of extraction and varimax rotation. All statistical analyses were performed by using the SYSTAT 10 software.

\section{Results and discussion}

\subsection{Pomological and physico-chemical parameters}

Physico-chemical data show a wide variability of the observed characteristics. However, the obtained results show how the ripening stage at harvest affects the final quality of the fruits in all the observed CVs. Concerning pomological parameters (Supporting Information: SUPP4), all observed CVs displayed high quality attributes, and GRN and MAT fruits did not differ significantly. In particular, all the varieties in question reach a considerable commercial size, with a rather small incidence of seed and peel on the total fruit weight. The edible part percentage ranged between $69 \%$ (Maya) and $82 \%$ (Rosa) of the total fruit weight. On the other hand, Rosa together to Manzanillo and Tommy Atkins produced the biggest fruits.

At mature-green harvest (GRN fruits at harvest), the fruits of all the observed CVs were similar in FF (Table 1) that varied in a tight range, from $7.1 \mathrm{~kg} \mathrm{~cm}^{-2}$ (Gleen) to $9.8 \mathrm{~kg} \mathrm{~cm}^{-2}$ (Maya). Following the 
Table 1

Flesh firmness (FF), total solid soluble content (TSS) and Titrated Acidity (TA) in GRN and MAT fruits of the nine observed Cvs. Values represented as mean \pm SD. For each column, within the same series (GRN at harvest, GRN or MAT), different lowercase letters indicate significantly different at $\mathrm{p} \leq 0.05$ as measured by Tukey's multiple range test. Letter "a" denotes the highest value. " $(\mathrm{p}<0.05)$ and ${ }^{* * *}(\mathrm{p}<0.001)$ indicate significantly differences between GRN at consume and MAT fruits (Student's $t$-test).

\begin{tabular}{|c|c|c|c|c|c|c|c|c|c|c|}
\hline & \multicolumn{4}{|l|}{$\mathrm{FF}\left(\mathrm{kg} \mathrm{cm}^{-2}\right)$} & \multicolumn{3}{|l|}{ TSS ( ${ }^{\circ}$ Brix) } & \multicolumn{3}{|c|}{ TA (g citric acid $\mathrm{L}^{-1}$ ) } \\
\hline & GNR (at harvest) & GRN & & MAT & GNR & & MAT & GNR & & MAT \\
\hline Carrie & $8.91 \pm 0.23^{\mathrm{bc}}$ & $2.23 \pm 0.18^{\mathrm{bc}}$ & & $1.81 \pm 0.24^{\mathrm{bc}}$ & $16.41 \pm 0.64^{\mathrm{a}}$ & * & $19.17 \pm 0.86^{\mathrm{a}}$ & $4.84 \pm 0.52^{\mathrm{cd}}$ & & $4.84 \pm 0.64^{\mathrm{ef}}$ \\
\hline Glenn & $7.13 \pm 0.41^{\mathrm{c}}$ & $1.47 \pm 0.06^{\mathrm{bc}}$ & & $1.18 \pm 0.16^{\mathrm{d}}$ & $11.32 \pm 0.52^{\mathrm{bc}}$ & * & $18.61 \pm 0.87^{\mathrm{ab}}$ & $5.01 \pm 0.36^{\mathrm{cd}}$ & & $5.31 \pm 0.52^{\mathrm{def}}$ \\
\hline Keitt & $7.45 \pm 0.02^{\mathrm{bc}}$ & $2.45 \pm 0.02^{\mathrm{b}}$ & " & $1.41 \pm 0.31^{\mathrm{bcd}}$ & $11.42 \pm 0.52^{\mathrm{bc}}$ & * & $14.43 \pm 0.91^{\mathrm{d}}$ & $10.14 \pm 0.44^{\mathrm{a}}$ & * & $11.03 \pm 0.52^{\mathrm{b}}$ \\
\hline Kensington Pride & $7.52 \pm 0.39^{\mathrm{bc}}$ & $2.48 \pm 0.05^{\mathrm{b}}$ & & $1.72 \pm 0.12^{\mathrm{bcd}}$ & $10.43 \pm 0.52^{\mathrm{c}}$ & * & $14.71 \pm 0.44^{\mathrm{d}}$ & $4.01 \pm 0.98^{\mathrm{cd}}$ & & $4.21 \pm 0.52^{\mathrm{ef}}$ \\
\hline Manzanillo & $8.01 \pm 0.56^{\mathrm{bc}}$ & $1.91 \pm 0.71^{\mathrm{abc}}$ & & $2.48 \pm 0.23^{\mathrm{a}}$ & $15.92 \pm 0.52^{\mathrm{a}}$ & * & $17.47 \pm 0.74^{\mathrm{ab}}$ & $4.84 \pm 0.71^{\mathrm{cd}}$ & * & $6.84 \pm 0.52^{\mathrm{cd}}$ \\
\hline Maya & $9.78 \pm 0.84^{\mathrm{a}}$ & $1.78 \pm 0.22^{\mathrm{abc}}$ & 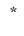 & $1.31 \pm 0.16^{\mathrm{cd}}$ & $17.31 \pm 0.52^{\mathrm{a}}$ & & $16.87 \pm 0.65^{\mathrm{bc}}$ & $4.01 \pm 0.12^{\mathrm{cd}}$ & & $4.01 \pm 0.52^{f}$ \\
\hline Osteen & $7.55 \pm 0.91^{\mathrm{bc}}$ & $3.55 \pm 0.18^{\mathrm{a}}$ & * & $1.88 \pm 0.17^{\mathrm{bc}}$ & $16.63 \pm 0.64^{\mathrm{a}}$ & & $17.71 \pm 0.57^{\mathrm{ab}}$ & $3.93 \pm 0.21^{\mathrm{d}}$ & * & $5.71 \pm 0.64^{\text {cde }}$ \\
\hline Rosa & $8.48 \pm 0.38^{\mathrm{abc}}$ & $1.61 \pm 0.27^{\mathrm{bc}}$ & 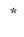 & $1.92 \pm 0.21^{\mathrm{ab}}$ & $12.31 \pm 0.64^{\mathrm{b}}$ & * & $15.02 \pm 0.41^{\mathrm{cd}}$ & $5.46 \pm 0.47^{\mathrm{c}}$ & $* *$ & $17.3 \pm 0.64^{\mathrm{a}}$ \\
\hline Tommy Atkins & $8.28 \pm 0.48^{\mathrm{abc}}$ & $1.15 \pm 0.24^{\mathrm{c}}$ & * & $1.51 \pm 0.18^{\mathrm{bcd}}$ & $16.81 \pm 0.64^{\mathrm{a}}$ & & $14.71 \pm 0.97^{\mathrm{d}}$ & $7.03 \pm 0.22^{\mathrm{b}}$ & & $7.31 \pm 0.64^{\mathrm{c}}$ \\
\hline
\end{tabular}

Table 2

Total carotenoid content (TCC), total polyphenolic content (TPC) and vitamin C content (VC) in GRN and MAT fruits of the nine observed Cvs of mango fruits. Values represented as mean \pm SD. For each column, within the same series (GRN or MAT) different lowercase letters indicate significantly different at $p \leq 0.05$ as measured by Tukey's multiple range test. Letter "a" denotes the highest value. " $(\mathrm{p}<0.05)$ and ${ }^{* *}(\mathrm{p}<0.001)$ indicate significantly differences between GRN and MAT fruits (Student's- $t$ test).

\begin{tabular}{|c|c|c|c|c|c|c|c|c|c|}
\hline & \multicolumn{3}{|c|}{ TCC ( $\mu \mathrm{g} \beta$-carotene eq per $\mathrm{g}$ of $\mathrm{FW}$ ) } & \multicolumn{3}{|c|}{ VC (mg AA per $100 \mathrm{~g}$ of FW) } & \multicolumn{3}{|c|}{ TPC (mg GAE per $100 \mathrm{~g}$ of FW) } \\
\hline & GRN & & MAT & GRN & & MAT & GRN & & MAT \\
\hline Carrie & $21.07 \pm 0.42^{\mathrm{a}}$ & $* *$ & $63.91 \pm 1.23^{\mathrm{a}}$ & $38.05 \pm 0.42^{\mathrm{a}}$ & $* *$ & $27.85 \pm 0.43^{\mathrm{a}}$ & $44.47 \pm 0.78^{\mathrm{a}}$ & * & $39.93 \pm 0.88^{b}$ \\
\hline Glenn & $12.89 \pm 0.33^{\mathrm{b}}$ & $* *$ & $17.53 \pm 0.36^{\mathrm{d}}$ & $21.22 \pm 0.25^{\mathrm{b}}$ & *** & $8.88 \pm 0.12^{f}$ & $38.88 \pm 0.72^{b}$ & * & $49.13 \pm 1.34^{\mathrm{a}}$ \\
\hline Keitt & $3.96 \pm 0.11^{\mathrm{de}}$ & & $3.69 \pm 0.04^{\mathrm{h}}$ & $21.78 \pm 0.27^{\mathrm{b}}$ & *** & $13.74 \pm 0.23^{\mathrm{d}}$ & $30.73 \pm 0.46^{\mathrm{d}}$ & ** & $17.99 \pm 0.13^{\mathrm{e}}$ \\
\hline Kensington Pride & $5.71 \pm 0.09^{\mathrm{de}}$ & $* *$ & $43.29 \pm 0.83^{\mathrm{b}}$ & $16.45 \pm 0.18^{\mathrm{d}}$ & $* *$ & $12.06 \pm 0.20^{\mathrm{e}}$ & $34.46 \pm 0.64^{c}$ & & $32.36 \pm 0.65^{c}$ \\
\hline Manzanillo & $1.42 \pm 0.06^{\mathrm{f}}$ & *** & $7.17 \pm 0.09^{g}$ & $20.35 \pm 0.31^{\mathrm{c}}$ & $* *$ & $12.06 \pm 0.17^{\mathrm{e}}$ & $35.62 \pm 0.70^{\mathrm{bc}}$ & ** & $23.92 \pm 0.41^{\mathrm{d}}$ \\
\hline Maya & $6.71 \pm 0.09^{\mathrm{cd}}$ & $* *$ & $33.20 \pm 0.67^{c}$ & $21.13 \pm 0.25^{\mathrm{bc}}$ & $* *$ & $9.16 \pm 0.15^{\mathrm{f}}$ & $43.42 \pm 0.84^{\mathrm{a}}$ & $*$ & $34.69 \pm 0.79^{c}$ \\
\hline Osteen & $1.38 \pm 0.07^{\mathrm{f}}$ & $* *$ & $13.64 \pm 0.12^{\mathrm{e}}$ & $6.98 \pm 0.17^{f}$ & $* *$ & $12.32 \pm 0.19^{\mathrm{e}}$ & $15.25 \pm 0.28^{\mathrm{f}}$ & ** & $27.42 \pm 0.59^{d}$ \\
\hline Rosa & $7.98 \pm 0.21^{\mathrm{cd}}$ & $* *$ & $14.89 \pm 0.36^{\mathrm{de}}$ & $4.10 \pm 0.10^{g}$ & $* *$ & $14.70 \pm 0.22^{\mathrm{c}}$ & $19.91 \pm 0.41^{\mathrm{e}}$ & $*$ & $23.81 \pm 0.37^{\mathrm{d}}$ \\
\hline Tommy Atkins & $2.62 \pm 0.09^{\mathrm{ef}}$ & $* *$ & $10.24 \pm 0.24^{f}$ & $9.11 \pm 0.18^{\mathrm{e}}$ & $* *$ & $16.18 \pm 0.26^{\mathrm{b}}$ & $21.77 \pm 0.50^{\mathrm{e}}$ & $* *$ & $35.56 \pm 0.74^{\mathrm{bc}}$ \\
\hline
\end{tabular}

indication of Lalel, Singh, and Tan (2003), we stored all the maturegreen fruits at $25^{\circ} \mathrm{C}$ for several days to permit them to reach the final ripening. Generally, MAT fruit were less firm in respect to GRN ones. In particular, GRN fruits possess better durability than the corresponding MAT fruits, especially for Osteen, Tommy Atkins, Keitt and Kensington Pride, which correspond to almost all the varietal offer imported from tropical countries (Table 1).

TSS varied largely among the analyzed genotypes, considering both GRN and MAT fruits (Table 1). In particular, GRN fruits can be grouped in two different subgroup: a group including Carrie, Manzanillo, Maya and Tommy Atkins always exceeding $15{ }^{\circ} \mathrm{Brix}$, and another group, including Glenn, Keitt and Kensington Pride, with TSS values that remained below $12.5^{\circ}$ Brix. Similar values were observed by de Cassia Mirela Resende Nassur et al. (2015). Excluding Tommy Atkins, TSS values of MAT fruits were higher than those of the corresponding GRN fruits and ranged from $14.4^{\circ}$ Brix (Kensington Pride) to over $18.0^{\circ}$ Brix (Carrie and Glenn).

At least, regards TA value, we did not observe significant differences between GRN and MAT fruits or value slightly higher for Keitt, Manzanillo and Osteen MAT fruit compared to GRN ones (Table 1). Just for Rosa MAT fruits, TA value was three times higher than the corresponding GRN fruits. The fruits of all the examined CVs showed TA values of less than $7 \mathrm{~g} / \mathrm{L}$ except Keitt, which reached values of more than $10 \mathrm{~g} / \mathrm{L}$ for both GRN and MAT fruits, and Rosa MAT fruits that exceeded $17 \mathrm{~g} / \mathrm{L}$.

Our results suggest that MAT fruits could satisfy better the needs of market and consumer. On the other hand, in some cases GRN fruits reached a quality level similar to the corresponding MAT ones. In particular, for Osteen, Tommy Atkins, Manzanillo, and Carrie, early harvesting and ripening after picking, made it possible to achieve qualitative attributes, in term of TSS and TA, similar to those of the MAT fruits.

\subsection{Bioactive compounds}

The potential beneficial effects of plant food consumption can be ascribed to a number of peculiar bioactive compounds (Gentile, Perrone, Attanzio, Tesoriere, \& Livrea, 2015; Naselli et al., 2015). On the other hand, phytochemical profile and content of individual phytochemicals are deeply influenced by genotype but also ripening stage and storage conditions play an important role (Avellone et al., 2018; Di Stefano et al., 2017, 2018; Dragovic-Uzelac, Levaj, Mrkic, Bursac, \& Boras, 2007). Studying how these variables affect quality parameters of the tropical fruits is especially useful considering their short shelf life. In our results, amounts of carotenoids, vitamin $\mathrm{C}$ and polyphenols in analyzed mango fruits largely varied as a function of genotype and ripening stage at harvest, with average values comparable to those previously reported for other mango CVs (Liu et al., 2013; Shivashankara, Isobe, Al-Haq, Takenaka, \& Shiina, 2004; Sulaiman \& Ooi, 2012).

As expected, carotenoid synthesis turned out to be higher during ripening at the tree with light exposure: MAT fruits showed significantly higher values when compared to the corresponding GRN ones (Table 2). The mean value of TCC in MAT fruits was $23.06 \mu$ g per $\mathrm{g}$ FW and, among the analyzed genotypes Carrie had the highest TCC, followed by Kensington Pride and Maya. On the contrary, GRN fruits displayed very low carotenoid levels, with a mean value of $7.08 \mu \mathrm{g}$ per $\mathrm{g}$ FW.

Concerning TPC, there were small differences between GRN and MAT fruits. Only for some CVs, fruits matured on the tree showed higher TPC than the corresponding GNR ones (Table 2). Among the 
analyzed genotypes, when considering the MAT fruits, Glenn had the highest TPC, followed by Carrie and Tommy Atkins. Conversely, for GRN fruits, Carrie was the CV with the highest TPC value, followed by Maya and Glenn.

Concerning VC, among the analyzed genotypes Carrie had the highest content for both ripening stages (Table 2). With the exception of Osteen, Rosa and Tommy Atkins, GRN fruits showed higher VC than the corresponding MAT ones. The content in antioxidant phytochemicals may decrease during ripening. This eventuality, already reported in mango fruits (Shivashankara et al., 2004; Sulaiman \& Ooi, 2012), can be related to several processes, including hydrolysis of tannins and increased polyphenol oxidase activity, that are typical of ripe fruits. On the other hand, before our work the effect of maturation of the ripening stage at harvest on nutraceutical parameters of ready to eat mango fruits have not been evaluated. The higher content in hydrophilic antioxidants in GRN fruits compared to the corresponding MAT fruits, which we showed for some of the analyzed CVs, indicates that ripening after harvest reduces antioxidant consumption with respect to ripening at the tree. In agreement with our findings, Shavashankara et al., showed a higher carotenoid content and a lower hydrophilic antioxidant content in MAT mango fruits of Irwin variety than in corresponding GRN fruits (Shivashankara et al., 2004). Similar results have been reported for other climacteric fruits (Campbell, Merwin, \& PadillaZakour, 2013). Our results therefore, in agreement with literature data, may indicate that ripening at the tree represent a higher oxidative stress condition for some CVs than for others. Direct light exposure may account for increased susceptibility to oxidative stress.

Polyphenolic profile of the fruit flesh of the observed nine mango CVs was studied using UHPLC-HESI-MS techniques. In our samples, we identified and quantify 9 phenolic compounds (Table 3). Although we found a comparable qualitative profile in the analyzed samples, our data showed, in agreement with literature data (López-Cobo et al., 2017; Ribeir et al., 2008), differences in the quantitative profile as a function of genotype and ripening stage at harvest. Vanillin and benzoic acid were among the most abundant polyphenol compounds in all the CVs in both GRN and MAT fruits. These compounds represented over $50 \%$ by weight of the total amount of phenolic compounds in all samples. Mangiferin, a natural C-glucosyl xanthone, with multiple documented biological activities (Rauf, Imranb, \& Patel, 2017), was present in all studied samples and in much larger quantities in the pulp of the CVs Manzanillo, Tommy Atkins, Glenn and Osteen, in GRN and MAT fruits, and in Rosa MAT fruits. Considering the effects of ripening on the evolution of the polyphenolic profile and content, our results showed very limited variations between GRN and MAT fruits. The CV for which major variations were measured is Glenn. For this CV the MAT fruits have a syringic acid and apigenin content about half of the corresponding MAT fruits. Considering mangiferin, in Osteen, Rosa and Tommy Atkins, the CVs with higher content, this polyphenol was more concentrated in MAT fruits than in corresponding GRN fruits. Similarly, benzoic acid content was higher in MAT fruits for Carrie and Tommy Atkins and, in contrast, lower in MAT fruits for Manzanillo.

The Principal Component Analysis (PCA), calculated on the data matrices reported in Tables 2 and 3, allowed the discrimination between the CVs, both in GRN and MAT series (Fig. 1). PCA explained $49.89 \%$ and $25.04 \%$ of the total variance for PC1 and PC2 for GRN fruits, meanwhile $38.10 \%$ and $21.51 \%$ for MAT fruits. Positive factor scores discriminated in GRN series Rosa and Osteen from others CVs for their lower content in total polyphenols, VC and p-coumaric acid. On the contrary, negative factor scores separated Gleen GRN for the highest content of studied phytochemicals. Positive PC1 and negative PC2 factor score grouped Keitt, Maya and Carrie for their lower mangiferin content. In the MAT series, positive factor scores separated Manzanillo, Rosa, Keitt and Osteen from other CVs for their lower TPC and organic acids content, mainly syringic and p-coumaric acid. Negative factor scores allow the discrimination of Gleen MAT fruits for higher TPC and in particular higher mangiferin content. Finally, the high content of benzoic acid allows the discrimination of Tommy Atkins and Carrie, meanwhile the lowest caffeic acid content discriminated Kensington Pride and Mawa from other CVs.

\subsection{Antioxidant properties}

Bioactivity of plant chemicals has been related especially to their antioxidant properties, which are not only useful to prevent oxidative stress phenomena but also influence intracellular redox status by modulating a number of important redox-dependent cell functions (Gentile et al., 2012; Tesoriere, Allegra, Gentile, \& Livrea, 2009). Our results showed a significant variability in radical-scavenging potential of the studied genotypes (Table 4). Regardless of the ripening stage at harvest, high TAA values were recorded for Glenn, Carrie, Maya and Kensington Pride. It is hard to compare our results with literature data because in other studies different methods were used for measuring reducing ability. However, for both GRN and MAT fruits TAA is positively correlated with TPC ( $p=0.94$ and $p=0.99$ for GRN and MAT fruits, respectively), which is instead comparable to what is reported in literature for other mango CVs (Shivashankara et al., 2004). In contrast, no significant correlations were observed between TAA and VC. These results indicate that the presence of significant amounts of phenolic compounds is a major contribution to the antioxidant activity of these fruits. For Carrie, Gleen, Osteen and Tommy Atkins TAA values of MAT fruits were higher than the corresponding GRN fruits. On the contrary, Manzanillo GRN fruits had TAA value higher than the corresponding MAT fruits. In most cases, the observed differences in TAA values between GRN and MAT fruits were consistent with the differences in content of hydrophilic antioxidants between the two ripening stages at harvest. On the other hand, Keitt and Maya MAT fruits displayed similar TAA values to the corresponding GRN fruits, in spite of the higher amounts of hydrophilic antioxidants in GRN fruits than in MAT ones. Unexpectedly, the antioxidant activity of Carrie, was higher in MAT fruits than in the corresponding GRN fruits, despite the latter presented a significantly higher polyphenolic content. The discrepancies in TAA and TPC values between GRN and MAT fruits observed for some CVs can be explained by the variability of the phytochemical profile among the observed CVs and a different ability of antioxidant compounds to reduce the ABTS free radical. In solution assays, although widely used for preliminary screening of radical-scavenging and antioxidant activities, are not always useful to make predictions of in vivo antioxidant activity. Indeed, those methods do not generate biological radicals nor evaluate the ability of antioxidants to interact with membranes and their stability physiological conditions. Instead, in vitro lipid peroxidation assays are very interesting systems to evaluate an antioxidant potential with a really physiologically relevance (Wolfe, 2008). For this reason here we used also the CAA assay to evaluate the antioxidant activity of ethanolic extracts of the GRN and MAT mango fruits. The results are shown in Table 4. Among GRN fruits. the highest antioxidant activity was reordered for Manzanillo, followed by Maya and Carrie. In MAT series, Rosa followed by Osteen and Manzanillo, displayed the highest activity. The average of CAA50 values were $46.22 \mathrm{mg} \mathrm{FW} / \mathrm{mL}$ and $46.68 \mathrm{mg} \mathrm{FW} / \mathrm{mL}$ cell medium for MAT and GRN fruit respectively. These values are very close to those determined by Kelly and Wolfe for the extracts obtained from other fruits (Wolfe, 2008). CAA50 is not correlated with TPC or TAA. Positive correlations have not consistently been reported in studies comparing TAA and CAA of plant extracts (Eberhardt, Kobira, Keck, Juvik, \& Jeffery, 2005; Wolfe, 2008), confirming that the antioxidant capacity evaluated in solution assays may not be predictive of the real antioxidant activity in biological environments. On the other hand, the failure in finding a positive correlation between CAA and TPC for the tested fruit extracts suggests that the observed differences in the polyphenolic profile and in the single polyphenol content of different CVs significantly influence their potential bioactivity. Additionally, our results show that CAA variation from GRN to MAT fruits for each $\mathrm{CV}$ is compatible with the 


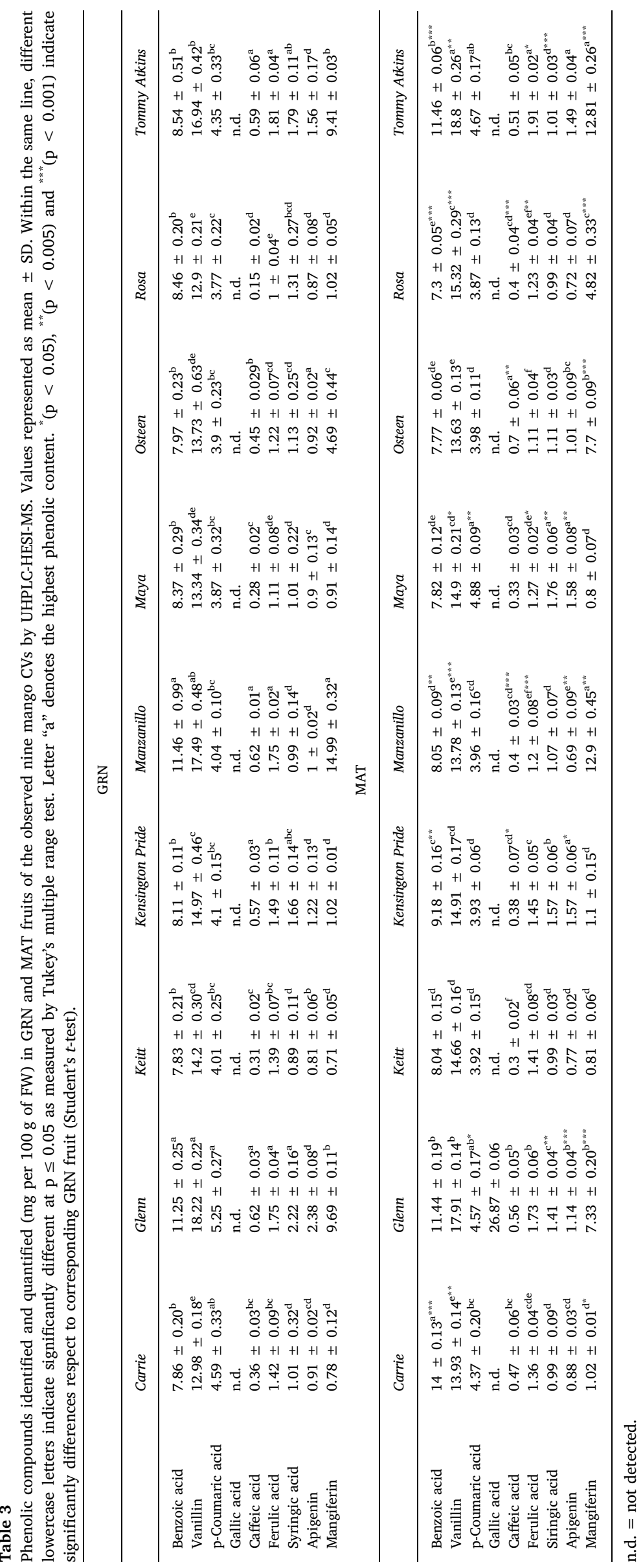



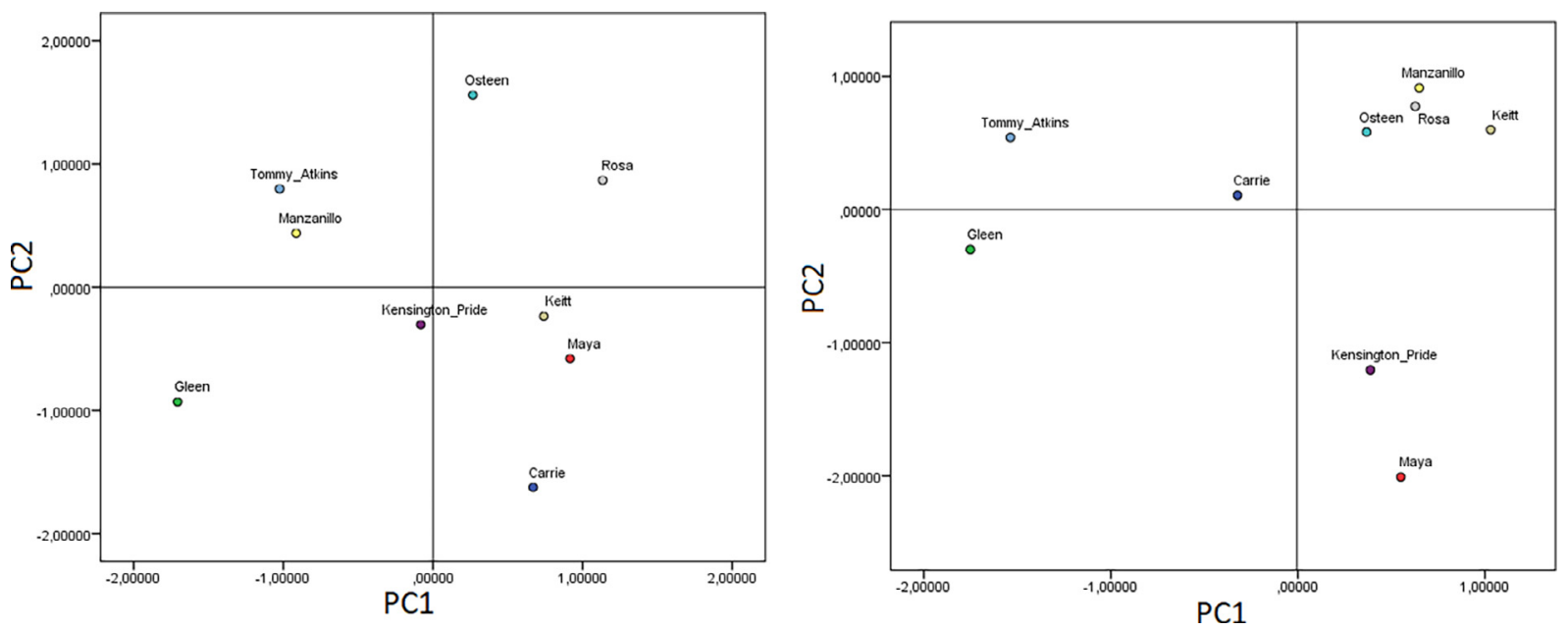

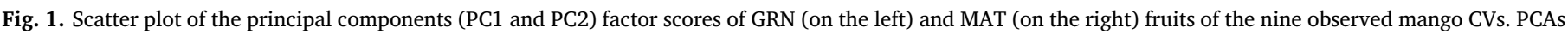
were performed using the data matrix of Tables 2 and 3.

Table 4

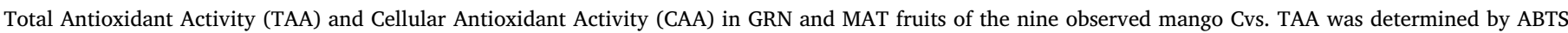

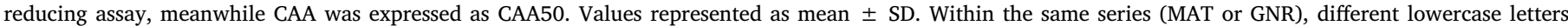

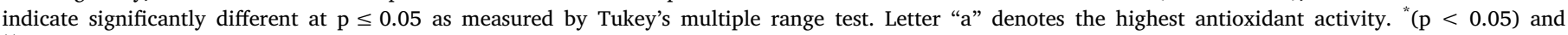
${ }^{* *}(\mathrm{p}<0.001)$ indicate significantly differences between MAT and GRN fruits (Student's $t$-test).

\begin{tabular}{|c|c|c|c|c|c|c|}
\hline & \multicolumn{3}{|c|}{ TAA $(\mu \mathrm{mol}$ TE per $100 \mathrm{~g}$ of FW) } & \multicolumn{3}{|c|}{ CAA50 ( $\mu \mathrm{g}$ of FW per mL of cell medium) } \\
\hline & GNR & & MAT & GNR & & MAT \\
\hline Carrie & $299.02 \pm 8.92^{\mathrm{a}}$ & * & $335.41 \pm 6.32^{\mathrm{b}}$ & $28.89 \pm 1.03^{\mathrm{bc}}$ & ** & $43.32 \pm 1.22^{\mathrm{c}}$ \\
\hline Glenn & $290.52 \pm 6.43^{\mathrm{a}}$ & $* *$ & $443.93 \pm 8.33^{\mathrm{a}}$ & $87.44 \pm 2.01^{g}$ & ** & $64.43 \pm 1.65^{\mathrm{d}}$ \\
\hline Keitt & $160.45 \pm 5.67^{\mathrm{c}}$ & & $145.90 \pm 3.47^{\mathrm{f}}$ & $42.17 \pm 1.45^{\mathrm{d}}$ & ** & $69.77 \pm 1.46^{\mathrm{d}}$ \\
\hline Kensington Pride & $236.89 \pm 5.96^{b}$ & & $255.14 \pm 8.32^{\mathrm{d}}$ & $58.65 \pm 1.76^{\mathrm{e}}$ & * & $67.13 \pm 1.54^{\mathrm{d}}$ \\
\hline Manzanillo & $281.11 \pm 7.03^{\mathrm{a}}$ & $* *$ & $184.93 \pm 4.87^{\mathrm{e}}$ & $13.54 \pm 0.44^{\mathrm{a}}$ & $* *$ & $21.43 \pm 0.65^{\mathrm{b}}$ \\
\hline Maya & $290.47 \pm 4.63^{\mathrm{a}}$ & & $294.50 \pm 7.62^{c}$ & $24.46 \pm 1.31^{\mathrm{bc}}$ & ** & $42.63 \pm 1.46^{\mathrm{c}}$ \\
\hline Osteen & $93.07 \pm 2.43^{\mathrm{d}}$ & $* *$ & $195.45 \pm 5.32^{\mathrm{e}}$ & $34.95 \pm 1.22^{c}$ & ** & $19.44 \pm 0.33^{\mathrm{ab}}$ \\
\hline Rosa & $162.68 \pm 4.32^{c}$ & & $174.68 \pm 5.43^{\mathrm{ef}}$ & $75.44 \pm 1.65^{\mathrm{f}}$ & $* *$ & $13.62 \pm 0.42^{\mathrm{a}}$ \\
\hline Tommy Atkins & $160.28 \pm 4.01^{c}$ & $* *$ & $306.77 \pm 9.70^{\mathrm{bc}}$ & $>125$ & ** & $82.09 \pm 1.87^{\mathrm{e}}$ \\
\hline
\end{tabular}

corresponding observed changes in TPC, as expected when considering that the qualitative polyphenolic profile for ripe fruit of each cultivar is the same regardless the ripening conditions.

\subsection{Sensory analysis}

Results from sensory profile (Table 5), showed that the observed CVs significantly differed also for all the evaluated sensory descriptors.

Peel color plays an important role in the perception of overall mango fruit quality (González-Aguilar, Buta, \& Wang, 2001). Regardless of the genotype, the judges considered the MAT fruits more colored in respect to GRN ones in both skin and flesh. Manzanillo, Maya and Gleen showed the best results with the best judgment, and they were the only CVs that reached good score (very intense) for skin and flesh color descriptors also in GRN fruits. For all observed genotypes, the acid taste was more intense in GRN fruit while, on the contrary, MAT fruit reached a sweeter taste. The panelists considered Keitt as the more acidic CV and Maya and Gleen as the sweeter in both GRN and MAT fruits. Regarding sweet descriptor of GNR fruits only Glenn, Maya, Osteen, and Tommy Atkins reached acceptable score. Sensory data confirmed chemical determinations: in particular, the best values of TSS/ TA ratio were observed in Maya (4.33), Carrie (3.39) for GRN and Osteen (4.50), Maya (4.22), Carrie (3.96) and Glenn (3.68) for MAT fruits. Keitt showed the lowest values both in GRN (1.03) and in MAT (1.42) fruits.

From a consumer point of view, exist a significant correlation between fiber presence and spooning ease (Galan Sauco \& Fernandez
Galvan, 1990) and the low-fiber CVs could be preferred by the consumer. Generally, the judge considered MAT fruits with a lower fiber content respect to corresponding GRN fruits. However, the differences between GRN and MAT were not significantly. Kensington Pride and Tommy Atkins showed the highest score for the fiber in the flesh descriptor. On the contrary, Carrie GNR fruits and Manzanillo, Osteen, and Rosa MAT ones showed the lowest fiber content. MAT fruits was generally juicier than GRN ones. Only Maya, Osteen and Tommy Atkins GRN fruits showed for the juiciness descriptor an acceptable score. Malundo et al. founded a positive relation between the level of juiciness in mango fruits and the flavor perception (Malundo, Shewfelt, Ware, \& Baldwin, 2001). Our data confirmed this tendency. According with a higher juiciness, MAT fruits showed higher scores of exotic fruit and peach flavor and odor descriptor than the corresponding GNR fruits. Moreover, the juiciest CVs Glenn, Maya and Osteen presented the highest scores of exotic fruit flavor descriptors, both for GRN and MAT fruit. Maya also showed the best values for peach odor descriptor in both GNR and MAT fruits.

\section{Conclusions}

In conclusion, the demonstrated sensorial and pomological attributes, together to interesting nutraceutical value of the analyzed fruits, indicated a real possibility to reach high quality fruits in the Mediterranean climate. However, our results showed a great variability also among the CVs.

In order to develop more appreciable and healthy products in a very 
Table 5

Sensorial descriptors of GRN and MAT fruits of the observed nine CVs. Values represented as mean \pm SD. For each column, within the same series, different lowercase letters indicate significantly different at $\mathrm{p} \leq 0.05$ as measured by Tukey's multiple range test. Letter "a" denotes the highest value. "( $\mathrm{p}<0.05)$ indicate significantly differences respect to the corresponding GNR fruits (Student's $t$-test).

GRN

\begin{tabular}{|c|c|c|c|c|c|c|c|c|c|}
\hline & Carrie & Gleen & Keitt & Kensington Pride & Manzanillo & Maya & Osteen & Rosa & Tommy Atkins \\
\hline Skin color & $2.33 \pm 0.63^{b}$ & $6.75 \pm 0.78^{\mathrm{a}}$ & $4.89 \pm 0.52^{\mathrm{ab}}$ & $4.75 \pm 0.78^{\mathrm{ab}}$ & $6.83 \pm 0.63^{\mathrm{a}}$ & $6.50 \pm 0.78^{\mathrm{a}}$ & $4.82 \pm 0.47^{\mathrm{ab}}$ & $4.01 \pm 0.63^{\mathrm{ab}}$ & $5.25 \pm 0.52^{\mathrm{ab}}$ \\
\hline Flesh color & $5.33 \pm 0.61^{\mathrm{c}}$ & $6.51 \pm 0.73^{b}$ & $4.89 \pm 0.49^{c}$ & $4.25 \pm 0.73^{c}$ & $7.33 \pm 0.61^{\mathrm{a}}$ & $6.00 \pm 0.73^{\mathrm{b}}$ & $6.64 \pm 0.44^{b}$ & $4.17 \pm 0.60^{c}$ & $4.50 \pm 0.45^{c}$ \\
\hline Acid & $4.50 \pm 0.68^{\mathrm{b}}$ & $4.25 \pm 0.83^{\mathrm{b}}$ & $6.00 \pm 0.56^{\mathrm{a}}$ & $3.00 \pm 0.83^{c}$ & $4.67 \pm 0.68^{b}$ & $3.50 \pm 0.83^{c}$ & $2.09 \pm 0.50^{\mathrm{d}}$ & $4.50 \pm 0.68^{\mathrm{b}}$ & $2.75 \pm 0.55^{\mathrm{d}}$ \\
\hline Sweet & $3.83 \pm 0.55^{c}$ & $6.25 \pm 0.68^{b}$ & $3.11 \pm 0.45^{\mathrm{d}}$ & $5.25 \pm 0.68^{\mathrm{bc}}$ & $4.17 \pm 0.55^{\mathrm{bc}}$ & $7.01 \pm 0.68^{\mathrm{a}}$ & $6.27 \pm 0.41^{\mathrm{b}}$ & $2.67 \pm 0.55^{\mathrm{d}}$ & $6.25 \pm 0.56^{\mathrm{b}}$ \\
\hline Fiber in the flesh & $1.67 \pm 0.65^{c}$ & $2.75 \pm 0.80^{\mathrm{b}}$ & $2.89 \pm 0.53^{\mathrm{b}}$ & $4.25 \pm 0.80^{\mathrm{a}}$ & $3.50 \pm 0.65^{b}$ & $3.00 \pm 0.80^{\mathrm{b}}$ & $2.55 \pm 0.48^{\mathrm{bc}}$ & $2.67 \pm 0.65^{\mathrm{bc}}$ & $5.00 \pm 0.52^{\mathrm{a}}$ \\
\hline Juiciness & $3.67 \pm 0.55^{\mathrm{bc}}$ & $6.50 \pm 0.68^{\mathrm{a}}$ & $2.78 \pm 0.45^{c}$ & $6.25 \pm 0.68^{\mathrm{ab}}$ & $3.50 \pm 0.55^{\mathrm{bc}}$ & $7.25 \pm 0.68^{\mathrm{a}}$ & $6.45 \pm 0.41^{\mathrm{a}}$ & $2.67 \pm 0.55^{c}$ & $6.75 \pm 0.45^{\mathrm{a}}$ \\
\hline Peach odor & $2.17 \pm 0.77^{\mathrm{c}}$ & $5.01 \pm 0.94^{\mathrm{ab}}$ & $3.67 \pm 0.63^{\mathrm{b}}$ & $4.00 \pm 0.94^{\mathrm{b}}$ & $2.67 \pm 0.77^{c}$ & $5.25 \pm 0.94^{\mathrm{a}}$ & $4.09 \pm 0.57^{\mathrm{b}}$ & $3.17 \pm 0.77^{\mathrm{c}}$ & $3.00 \pm 0.68^{c}$ \\
\hline Exotic Fruit odor & $5.04 \pm 0.62^{\mathrm{ab}}$ & $5.75 \pm 0.76^{\mathrm{ab}}$ & $3.44 \pm 0.51^{\mathrm{b}}$ & $6.02 \pm 0.76^{\mathrm{ab}}$ & $5.50 \pm 0.62^{\mathrm{ab}}$ & $5.50 \pm 0.76^{\mathrm{ab}}$ & $7.09 \pm 0.46^{\mathrm{a}}$ & $4.33 \pm 0.62^{\mathrm{b}}$ & $3.50 \pm 0.65^{b}$ \\
\hline Peach flavor & $3.09 \pm 0.77^{\mathrm{c}}$ & $5.25 \pm 0.94^{\mathrm{ab}}$ & $3.56 \pm 0.63^{\mathrm{b}}$ & $4.55 \pm 0.94^{\mathrm{b}}$ & $3.67 \pm 0.77^{\mathrm{bc}}$ & $6.25 \pm 0.94^{\mathrm{a}}$ & $3.27 \pm 0.57^{\mathrm{b}}$ & $3.09 \pm 0.77^{c}$ & $4.02 \pm 0.68^{\mathrm{b}}$ \\
\hline \multirow{2}{*}{$\begin{array}{l}\text { Exotic Fruit flavor } \\
\text { MAT }\end{array}$} & $5.08 \pm 0.63^{\mathrm{ab}}$ & $6.25 \pm 0.77^{\mathrm{a}}$ & $3.67 \pm 0.51^{\mathrm{c}}$ & $6.25 \pm 0.77^{\mathrm{a}}$ & $4.67 \pm 0.63^{b}$ & $6.51 \pm 0.77^{\mathrm{a}}$ & $6.73 \pm 0.47^{\mathrm{a}}$ & $4.03 \pm 0.63^{c}$ & $4.75 \pm 0.65^{\mathrm{b}}$ \\
\hline & Carrie & Gleen & Keitt & Kensington Pride & Manzanillo & Maya & Osteen & Rosa & Tommy Atkins \\
\hline Skin color ${ }^{*}$ & $5.31 \pm 0.52^{\mathrm{c}}$ & $8.02 \pm 0.82^{\mathrm{a}}$ & $7.33 \pm 0.55^{\mathrm{a}}$ & $6.01 \pm 0.82^{\mathrm{b}}$ & $8.10 \pm 0.67^{\mathrm{a}}$ & $8.51 \pm 0.82^{\mathrm{a}}$ & $4.64 \pm 0.49^{c}$ & $7.83 \pm 0.67^{\mathrm{a}}$ & $6.51 \pm 0.82^{\mathrm{b}}$ \\
\hline Flesh color ${ }^{*}$ & $6.25 \pm 0.46^{\mathrm{b}}$ & $7.25 \pm 0.73^{\mathrm{ab}}$ & $7.56 \pm 0.49^{\mathrm{a}}$ & $5.25 \pm 0.73^{\mathrm{b}}$ & $8.17 \pm 0.60^{\mathrm{a}}$ & $8.51 \pm 0.73^{\mathrm{a}}$ & $6.82 \pm 0.44^{\mathrm{ab}}$ & $5.67 \pm 0.60^{\mathrm{b}}$ & $7.00 \pm 0.73^{\mathrm{ab}}$ \\
\hline Acid $^{*}$ & $1.70 \pm 0.43^{\mathrm{c}}$ & $2.25 \pm 0.67^{\mathrm{b}}$ & $3.11 \pm 0.45^{\mathrm{a}}$ & $2.00 \pm 0.67^{\mathrm{bc}}$ & $1.83 \pm 0.55^{c}$ & $2.50 \pm 0.67^{b}$ & $1.82 \pm 0.41^{\mathrm{c}}$ & $1.67 \pm 0.55^{\mathrm{c}}$ & $2.25 \pm 0.67^{\mathrm{b}}$ \\
\hline Sweet" & $8.20 \pm 0.40^{\mathrm{a}}$ & $8.50 \pm 0.63^{\mathrm{a}}$ & $6.44 \pm 0.42^{\mathrm{ab}}$ & $6.25 \pm 0.63^{\mathrm{ab}}$ & $7.50 \pm 0.52^{\mathrm{ab}}$ & $8.50 \pm 0.63^{\mathrm{a}}$ & $6.73 \pm 0.38^{\mathrm{ab}}$ & $5.33 \pm 0.52^{\mathrm{b}}$ & $6.50 \pm 0.63^{\mathrm{ab}}$ \\
\hline Fiber in the flesh & $2.00 \pm 0.49^{b c}$ & $2.50 \pm 0.78^{\mathrm{b}}$ & $3.33 \pm 0.52^{\mathrm{ab}}$ & $4.75 \pm 0.78^{\mathrm{a}}$ & $1.83 \pm 0.63^{b c}$ & $2.25 \pm 0.78^{\mathrm{bc}}$ & $1.64 \pm 0.47^{\mathrm{c}}$ & $1.67 \pm 0.63^{\mathrm{bc}}$ & $4.75 \pm 0.78^{\mathrm{a}}$ \\
\hline Juiciness" & $7.20 \pm 0.46^{\mathrm{ab}}$ & $8.50 \pm 0.73^{\mathrm{a}}$ & $6.44 \pm 0.49^{\mathrm{b}}$ & $6.50 \pm 0.73^{\mathrm{b}}$ & $6.17 \pm 0.60^{\mathrm{b}}$ & $8.50 \pm 0.73^{\mathrm{a}}$ & $7.55 \pm 0.44^{\mathrm{ab}}$ & $5.67 \pm 0.60^{c}$ & $7.25 \pm 0.73^{\mathrm{ab}}$ \\
\hline Peach odor ${ }^{*}$ & $4.72 \pm 0.71^{\mathrm{b}}$ & $6.51 \pm 1.12^{\mathrm{a}}$ & $4.56 \pm 0.74^{c}$ & $5.25 \pm 1.12^{\mathrm{b}}$ & $4.17 \pm 0.91^{\mathrm{c}}$ & $6.25 \pm 1.12^{\mathrm{a}}$ & $3.64 \pm 0.67^{c}$ & $2.67 \pm 0.91^{\mathrm{c}}$ & $3.75 \pm 1.12^{\mathrm{c}}$ \\
\hline Exotic Fruit odor" & $7.40 \pm 0.54^{\mathrm{a}}$ & $7.75 \pm 0.85^{\mathrm{a}}$ & $6.67 \pm 0.57^{b}$ & $6.75 \pm 0.85^{\mathrm{b}}$ & $7.33 \pm 0.69^{\mathrm{a}}$ & $7.51 \pm 0.85^{\mathrm{a}}$ & $7.10 \pm 0.51^{\mathrm{a}}$ & $4.83 \pm 0.69^{c}$ & $4.25 \pm 0.85^{c}$ \\
\hline Peach flavor ${ }^{*}$ & $4.44 \pm 0.76^{\mathrm{b}}$ & $6.25 \pm 1.21^{\mathrm{a}}$ & $5.06 \pm 0.82^{\mathrm{b}}$ & $4.75 \pm 1.22^{\mathrm{b}}$ & $4.17 \pm 0.98^{\mathrm{b}}$ & $7.02 \pm 1.22^{\mathrm{a}}$ & $3.64 \pm 0.72^{\mathrm{c}}$ & $2.17 \pm 0.98^{c}$ & $4.25 \pm 1.22^{\mathrm{c}}$ \\
\hline Exotic Fruit flavor" & $6.8 \pm 0.45^{\mathrm{ab}}$ & $7.25 \pm 0.72^{\mathrm{a}}$ & $6.56 \pm 0.48^{\mathrm{b}}$ & $6.5 \pm 0.72^{\mathrm{b}}$ & $7.83 \pm 0.59^{\mathrm{a}}$ & $8.25 \pm 0.72^{\mathrm{a}}$ & $7.73 \pm 0.43^{\mathrm{a}}$ & $4.17 \pm 0.59^{c}$ & $4.75 \pm 0.72^{\mathrm{c}}$ \\
\hline
\end{tabular}

crowded market, our data may be of interest to plant breeders. Moreover, as expected, our physico-chemical, sensorial and nutraceutical analyses showed that the time of harvest affects the final fruit quality. MAT fruits showed high pomological and sensorial traits and are better suited for short supply chains; meanwhile fruits harvested at commercial ripening and matured after harvest, are firmer and consequently can stand long storage and shipping. On the other hand, GRN fruits frequently achieve higher nutraceutical value and, in a cultivar-dependent manner, can reach pomological and sensory characteristics close to those of corresponding MAT fruits, and compatible with the market demand and consumer taste. Overall, the obtained data contribute to define the commercial potential of the analyzed genotypes and to identify the most suitable fruits to be ripened after harvest and then the best market for each CV.

\section{Acknowledgements}

The authors acknowledge Pietro Cuccio, owner of Cupitur s. r. 1., for the technical support and for its kind hospitality.

\section{Conflict of interest}

The authors declare no conflict of interest.

\section{Appendix A. Supplementary data}

Supplementary data to this article can be found online at https:// doi.org/10.1016/j.foodchem.2018.10.109.

\section{References}

Ali, M. A., Devi, L. I., Nayan, V., Chanu, K. V., \& Ralte, L. (2010). Antioxidant activity of fruits available in Aizawl market of Mizoram, India. International Journal of Biological and Pharmaceutical, 1(2), 76-81.

Avellone, G., Salvo, A., Costa, R., Saija, E., Bongiorno, D., Di Stefano, V., ... Dugo, G. (2018). Investigation on the influence of spray-drying technology on the quality of Sicilian Nero d'Avola wines. Food Chemistry, 240(July 2017), 222-230. https://doi. org/10.1016/j.foodchem.2017.07.116.
Bauernfeind, J. C. (1981). Carotenoids as colorants and vitamin A precursors; technological and nutritional applications.

Campbell, O. E., Merwin, I. A., \& Padilla-Zakour, O. I. (2013). Characterization and the effect of maturity at harvest on the phenolic and carotenoid content of Northeast USA apricot (Prunus armeniaca) varieties. Journal of Agricultural and Food Chemistry, 61(51), 12700-12710. https://doi.org/10.1021/jf403644r.

de Cassia Mirela Resende Nassur, R., González-Moscoso, S., Crisosto, G. M., de Oliveira Lima, L. C., de Barros Vilas Boas, E. V., \& Crisosto, C. H. (2015). Describing quality and sensory attributes of 3 mango (Mangifera indica L.) cultivars at 3 ripeness stages based on firmness. Journal of Food Science, 80(9), 2055-2063. https://doi.org/10. 1111/1750-3841.12989.

Di Stefano, V., Avellone, G., Bongiorno, D., Cunsolo, V., Muccilli, V., Sforza, S., ... Vékey, K. (2012). Applications of liquid chromatography-mass spectrometry for food analysis. Journal of Chromatography A, 1259, 74-85. https://doi.org/10.1016/j.chroma. 2012.04.023.

Di Stefano, V., Avellone, G., Bongiorno, D., Indelicato, S., Massenti, R., \& Lo Bianco, R. (2017). Quantitative evaluation of the phenolic profile in fruits of six avocado (Persea americana) cultivars by ultra-high-performance liquid chromatography-heated electrospray-mass spectrometry. International Journal of Food Properties, 20(6), 1302-1312. https://doi.org/10.1080/10942912.2016.1208225.

Di Stefano, V., Pitonzo, R., Novara, M. E., Bongiorno, D., Indelicato, S., Gentile, C., ... Melilli, M. G. (2018). Antioxidant activity and phenolic composition in Pomegranate (Punica granatum L.) genotypes from south Italy by UHPLC/Orbitrap-MS approach. Journal of the Science of Food and Agriculture. https://doi.org/10.1002/jsfa.9270.

Dragovic-Uzelac, V., Levaj, B., Mrkic, V., Bursac, D., \& Boras, M. (2007). The content of polyphenols and carotenoids in three apricot cultivars depending on stage of maturity and geographical region. Food Chemistry, 102(3), 966-975. https://doi.org/10.1016/ j.foodchem.2006.04.001.

Eberhardt, M. V., Kobira, K., Keck, A. S., Juvik, J. A., \& Jeffery, E. H. (2005). Correlation analyses of phytochemical composition, chemical, and cellular measures of antioxidant activity of broccoli (Brassica oleracea L. Var. italica). Journal of Agricultural and Food Chemistry, 53(19), 7421-7431. https://doi.org/10.1021/jf051495k.

Farina, V., D'Asaro, A., Mazzaglia, A., Gianguzzi, G., \& Palazzolo, E. (2017a). Chemicalphysical and nutritional characteristics of mature-green and mature-ripe "Kensington Pride" mango fruit cultivated in Mediterranean area during cold storage. Fruits, 72(4), 221-229. https://doi.org/10.17660/th2017/72.4.4

Farina, V., Gianguzzi, G., D’Asaro, A., Mazzaglia, A., \& Palazzolo, E. (2017b). Fruit production and quality evaluation of four litchi cultivars (Litchi chinensis Sonn.) grown in Mediterranean climate. Fruits, 72(4), 203-211.

Farina, V., Tripodo, L., Gianguzzi, G., Sortino, G., Giuffre, D., Lo Cicero, U., ... Collura, A. (2017c). Innovative techniques to reduce chilling injuries in mango (Mangifera Indica L.) trees under mediterranean climate. Chemical Engineering Transactions, 58(September), https://doi.org/10.3303/CET1758138.

Galan Sauco, V. (2009). El cultivo del mango (2th ed.). La Laguna, Tenerife: Grupo MundiPrensa.

Galan Sauco, V., \& Fernandez Galvan, D. (1990). Differences between mango cultivars regarding their facility to be halved and spoon-eaten, and association with fiber Fruits, 45(4), 381-385. 
Gentile, C., Allegra, M., Angileri, F., Pintaudi, A. M., Livrea, M. A., \& Tesoriere, L. (2012). Polymeric proanthocyanidins from Sicilian pistachio (Pistacia vera L.) nut extract inhibit lipopolysaccharide-induced inflammatory response in RAW 264.7 cells. European Journal of Nutrition, 51(3), 353-363. https://doi.org/10.1007/s00394-0110220-5.

Gentile, C., Perrone, A., Attanzio, A., Tesoriere, L., \& Livrea, M. A. (2015). Sicilian pistachio (Pistacia vera L.) nut inhibits expression and release of inflammatory mediators and reverts the increase of paracellular permeability in IL-1 $\beta$-exposed human intestinal epithelial cells. European Journal of Nutrition, 54(5), 811-821. https://doi. org/10.1007/s00394-014-0760-6.

Gentile, C., Reig, C., Corona, O., Todaro, A., Mazzaglia, A., Perrone, A., ... Farina, V. (2016). Pomological traits, sensory profile and nutraceutical properties of nine cultivars of loquat (Eriobotrya japonica Lindl.) fruits grown in Mediterranean area. Plant Foods for Human Nutrition, 71(3), 330-338. https://doi.org/10.1007/s11130-0160564-3.

González-Aguilar, G. A., Buta, J. G., \& Wang, C. Y. (2001). Methyl jasmonate reduces chilling injury symptoms and enhances colour development of "Kent" mangoes. Journal of the Science of Food and Agriculture, 81(13), 1244-1249. https://doi.org/10. $1002 /$ jsfa. 933.

Kader, A., \& Mitcham, B. (2008). Optimum procedures for ripening mangoes. In Fruit ripening and ethylene management. Univ. Calif. postharvest technology research and information center publication series, 9 (pp 47-48).

Wolfe, Kelly L. (2008). Cellular antioxidant activity of common fruits. Journal of Agricultural and Food Chemistry, 8418-8426.

Lalel, H. J. D., Singh, Z., \& Tan, S. C. (2003). Aroma volatiles production during fruit ripening of "Kensington Pride" mango. Postharvest Biology and Technology, 27(3), 323-336. https://doi.org/10.1016/S0925-5214(02)00117-5.

Liu, F. X., Fu, S. F., Bi, X. F., Chen, F., Liao, X. J., Hu, X. S., \& Wu, J. H. (2013). Physicochemical and antioxidant properties of four mango (Mangifera indica L.) cultivars in China. Food Chemistry, 138(1), 396-405. https://doi.org/10.1016/j.foodchem.2012. 09.111.

López-Cobo, A., Verardo, V., Diaz-de-Cerio, E., Segura-Carretero, A., FernándezGutiérrez, A., \& Gómez-Caravaca, A. M. (2017). Use of HPLC- and GC-QTOF to determine hydrophilic and lipophilic phenols in mango fruit (Mangifera indica L.) and its by-products. Food Research International, 100, 423-434. https://doi.org/10.1016/ j.foodres.2017.02.008.

Malundo, T. M. M., Shewfelt, R. L., Ware, G. O., \& Baldwin, E. A. (2001). Sugars and acids influence flavor properties of mango (Mangifera indica). Retrieved from Journal of the American Society of Horticultural Science, 126(1), 115-121. http://journal. ashspublications.org/content/126/1/115.short.

Miller, N. J., \& Rice-Evans, C. A. (1996). Spectrophotometric determination of antioxidant activity. Redox Report, 2(3), 161-171. https://doi.org/10.1080/13510002. 1996.11747044.

Mirellys, J., Souza, A., Leonel, S., Modesto, J. H., Ferraz, R. A., Henrique, B., \& Gonçalves, L. (2015). Phenological cycles, thermal time and growth curves of mango fruit cultivars in subtropical conditions. Current Journal of Applied Science and Technology, 9(1), 100-107. https://doi.org/10.9734/BJAST/2015/18239.
Naselli, F., Belshaw, N. J., Gentile, C., Tutone, M., Tesoriere, L., Livrea, M. A., \& Caradonna, F. (2015). Phytochemical indicaxanthin inhibits colon cancer cell growth and affects the DNA methylation status by influencing epigenetically modyfying enzme expression and activity. Journal of Nutrigenetics and Nutrigenomics, 8(3), 114-127. https://doi.org/10.1159/000439382.

Pott, I., Marx, M., Neidhart, S., Mühlbauer, W., \& Carle, R. (2003). Quantitative determination of $\beta$-carotene stereoisomers in fresh, dried, and solar-dried mangoes (Mangifera indica L.). Journal of Agricultural and Food Chemistry, 51(16), 4527-4531. https://doi.org/10.1021/jf034084h.

Rauf, A., Imranb, M., \& Patel, S. (2017). Mangiferin: A phytochemical with panacea potential. Biomedicine and Pharmacotherapy, 96, 1562-1564. https://doi.org/10. 1016/j.biopha.2017.07.031.

Re, R., Pellegrini, N., Proteggente, A., Pannala, A., Yang, M., \& Rice-Evans, C. (1999). Antioxidant activity applying an improved ABTS radical cation decolorization assay. Free Radical Biology and Medicine, 26(9-10), 1231-1237.

Ribeiro, S. M. R., Barbosa, L. C. A., Queiroz, J. H., Knödler, M., \& Schieber, A. (2008). Phenolic compounds and antioxidant capacity of Brazilian mango (Mangifera indica L.) varieties. Food Chemistry, 110(3), 620-626. https://doi.org/10.1016/j.foodchem. 2008.02.067.

Rocha Ribeiro, S. M., Queiroz, J. H., Lopes Ribeiro de Queiroz, M. E., Campos, F. M., \& Pinheiro Sant'Ana, H. M. (2007). Antioxidant in mango (Mangifera indica L.) pulp. Plant Foods for Human Nutrition, 62(1), 13-17. https://doi.org/10.1007/s11130-0060035-3.

Shivashankara, K. S., Isobe, S., Al-Haq, M. I., Takenaka, M., \& Shiina, T. (2004). Fruit antioxidant activity, ascorbic acid, total phenol, quercetin, and carotene of Irwin mango fruits stored at low tempertaure after high electric field pretreatment. Journal of Agricultural and Food Chemistry, 52(5), 1281-1286. https://doi.org/10.1021/ jf0302431.

Singleton, V. L., \& Rossi, J. A. (1965). Colorimetry of total phenolics with phosphomolybdic-phosphotungstic acid reagents. American Journal of Enology and Viticulture, 16(3), 144-158.

Sulaiman, S. F., \& Ooi, K. L. (2012). Polyphenolic and vitamin C contents and antioxidant activities of aqueous extracts from mature-green and ripe fruit fleshes of mangifera SP. Journal of Agricultural and Food Chemistry, 60(47), 11832-11838. https://doi.org/ 10.1021/jf303736h.

Tesoriere, L., Allegra, M., Gentile, C., \& Livrea, M. A. (2009). Betacyanins as phenol antioxidants. Chemistry and mechanistic aspects of the lipoperoxyl radical-scavenging activity in solution and liposomes. Free Radical Research, 43(8), 706-717. https://doi.org/10.1080/10715760903037681.

Wanitchang, P., Terdwongworakul, A., Wanitchang, J., \& Nakawajana, N. (2011). Nondestructive maturity classification of mango based on physical, mechanical and optical properties. Journal of Food Engineering, 105(3), 477-484. https://doi.org/10. 1016/j.jfoodeng.2011.03.006.

Wolfe, K. L., \& Liu, R. H. (2007). Cellular antioxidant activity (CAA) assay for assessing antioxidants, foods, and dietary supplements. Journal of Agricultural and Food Chemistry, 55(22), 8896-8907. https://doi.org/10.1021/jf0715166. 